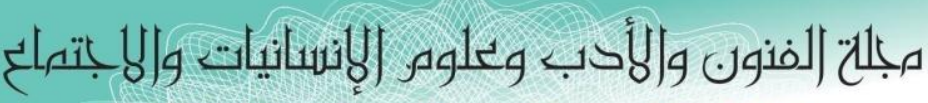
Journal of Arts, Literature, Humanities and Social Sciences

ISSN online: 2414 - 3383

ISSN print: 2616 - 3810

ديسمبر 2019

العدد (47)

Volume (47)

December 2019

\title{
المنهج المدرسي في الاتجاه التظري الاجتماعي
}

م.د. احمد عبد الكاظم كريم

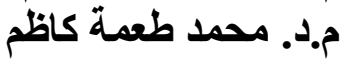

يهذف البحث الى التعرف على التجارب و الخبرات الواردة في الاتجاه النظري الاجتماعي للمنهج المدرسي .

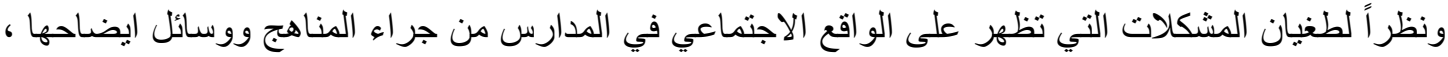

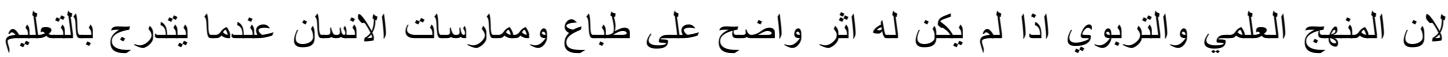

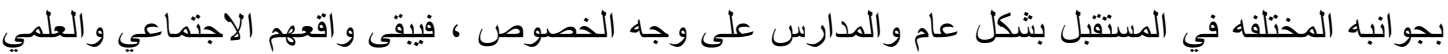

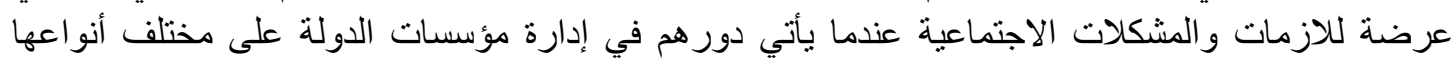

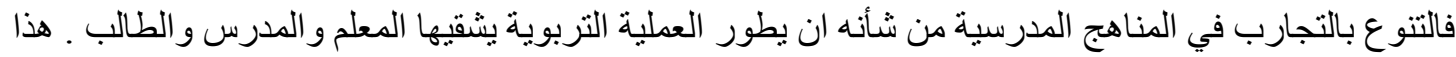

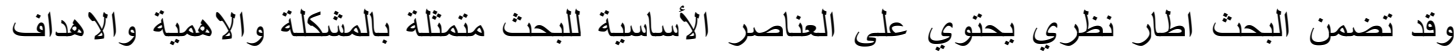

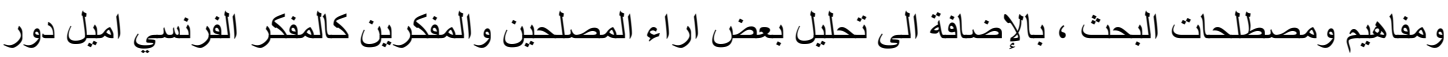

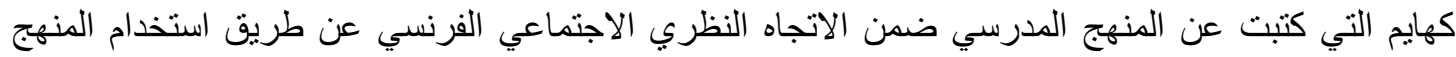

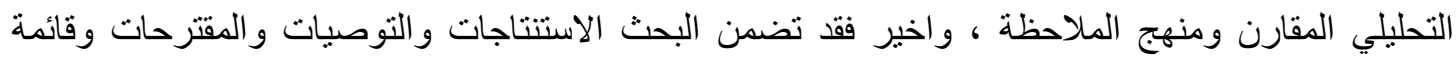

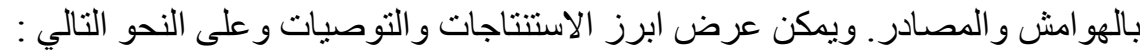

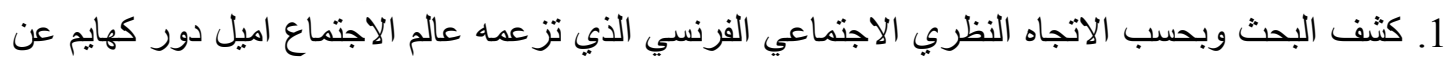

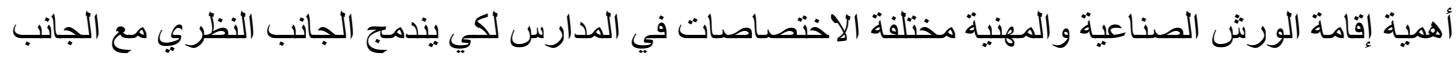

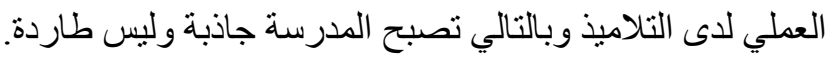

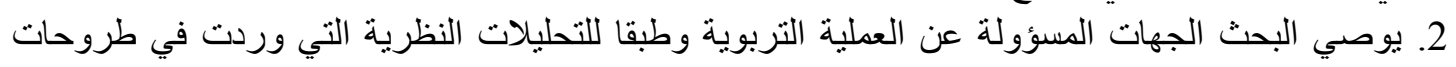

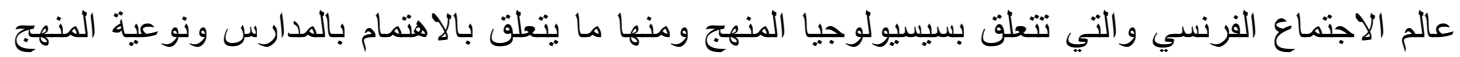

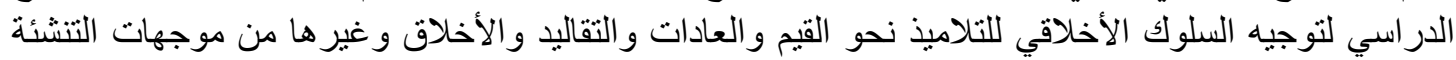

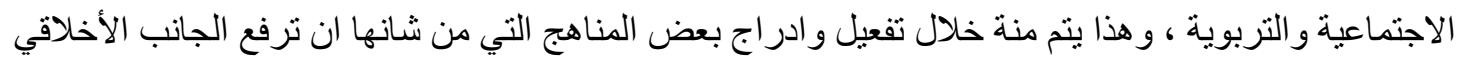

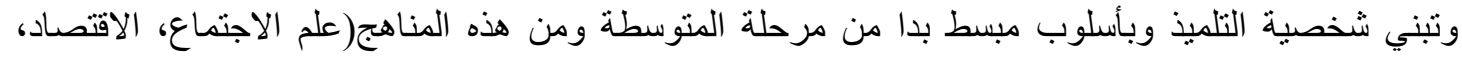

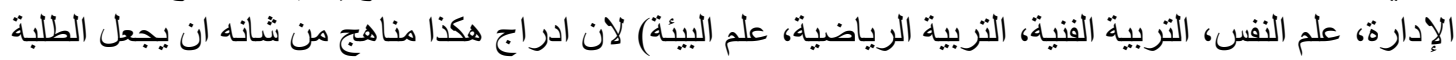

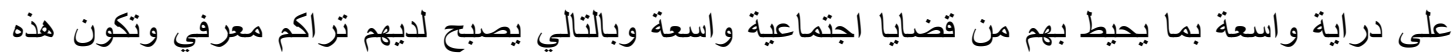

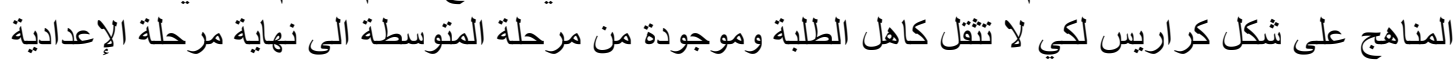

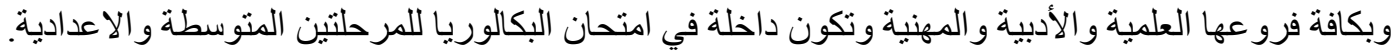




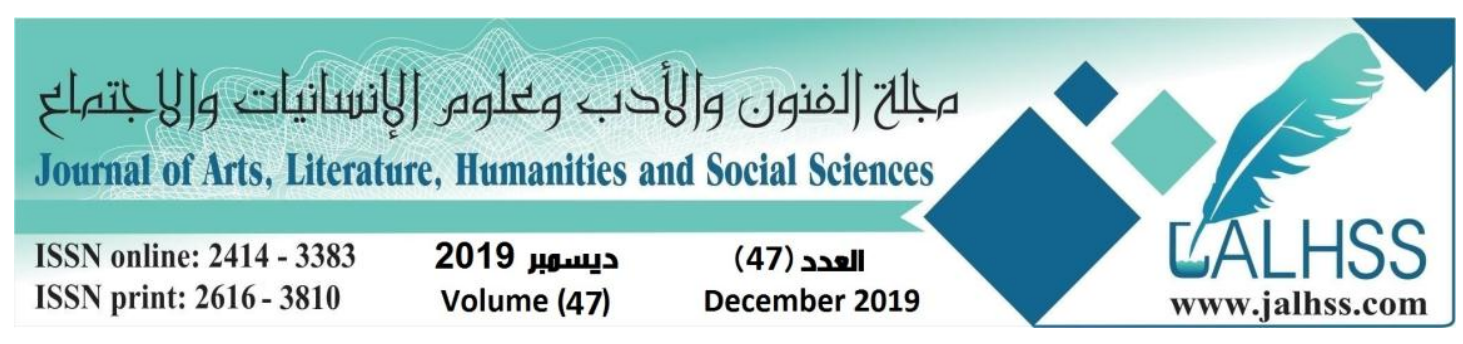

\title{
School Curriculum in Social Theoretical Direction
}

\author{
Dr. Ahmed A. Kareem \\ Dr. Muhammed T. KAdhim
}

\begin{abstract}
The research aims to identify the experiences and experiences contained in the social theoretical direction of the school curriculum. Given the prevalence of the problems that appear on the social reality in schools as a result of curricula and means of clarification, because the scientific and educational curriculum if it does not have a clear impact on the nature and practices of human beings when graduating education in various aspects in the future in general and schools in particular, their social and scientific reality remains vulnerable to crises And social problems when it comes to their role in the management of state institutions of all kinds of diversity experiences in the school curriculum would develop the educational process Ichkha teacher, teacher and student. This research included a theoretical framework containing the basic elements of the research represented by the problem, importance, objectives, concepts and terms of research, in addition to the analysis of some of the views of reformers and thinkers such as the French thinker Emile D'or Kaheim, who wrote about the school curriculum within the theoretical socio-French direction through the use of comparative analytical and observational approaches, Finally, the research included conclusions, recommendations, proposals and a list of margins and sources. The main conclusions and recommendations can be presented as follows:

1.The research, according to the French social theoretical direction led by sociologist Emil D'or Kaheim, revealed the importance of holding industrial and professional workshops in different disciplines in order to integrate the theoretical side with the practical side of the pupils.

2. The research recommends the bodies responsible for the educational process and according to the theoretical analyzes contained in the French sociologist's propositions, which relate to the psychology of the curriculum, including with regard to attention to schools and the quality of the curriculum to guide the moral behavior of students towards values, customs, traditions, ethics and other directives of socialization and education, and this is done through Activate and incorporate some curricula that will raise the moral aspect and adopt the personality of the student in a simplified manner started from the intermediate stage and these curricula (sociology, economics, management, psychology, art education, education For sports, ecology) because the inclusion of such curricula would make students aware of the broad surrounding social issues and thus have accumulation of knowledge and these curricula in the form of pamphlets so as not to burden students and exist from the middle to the end of the preparatory stage and all its branches Scientific, literary and professional and be included in the baccalaureate exam for the intermediate and preparatory stages.
\end{abstract}


مبلحت (لفنون والأدب وعلوه الإنسانيات والبانتهاع Journal of Arts, Literature, Humanities and Social Sciences

ISSN online: 2414 - 3383

ISSN print: 2616 - 3810
2019 ديسمبر

Volume (47)
(47) العدم)

December 2019

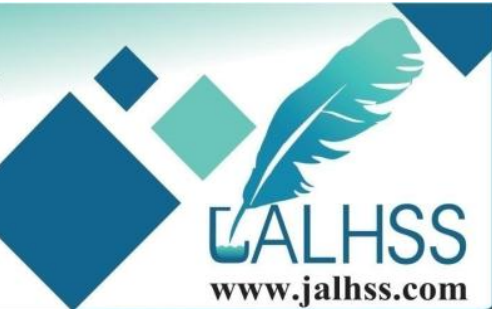

اولاً : المقدمة

فالمناهج العر اقية ظلت منذ ان تأسست الدولة العر اقية و الى الوقت الحالي ، تسير ضمن التجربة التهبة البريطانية في

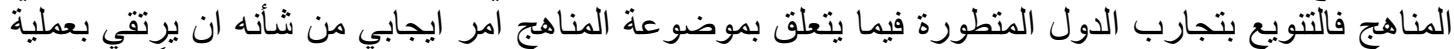

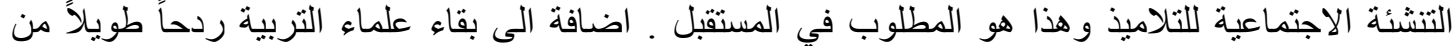

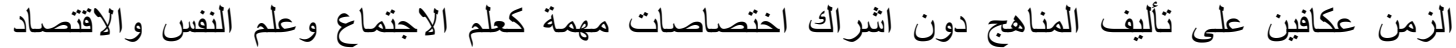

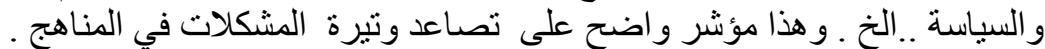

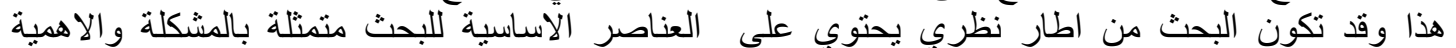

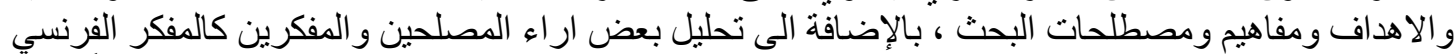

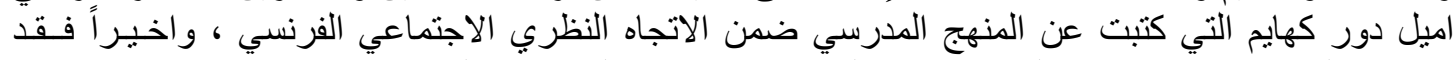

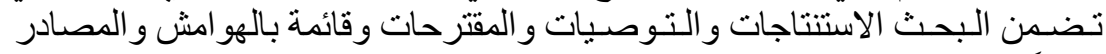

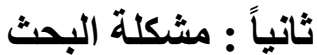

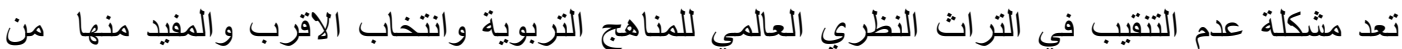

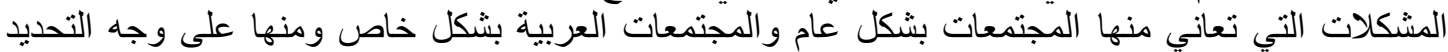

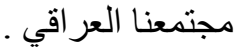

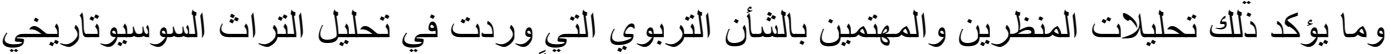

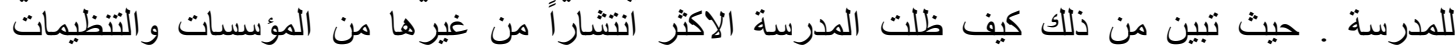

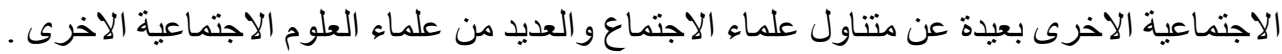

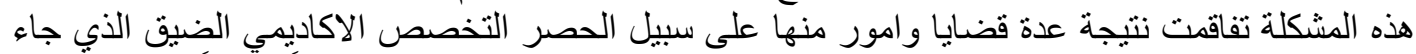

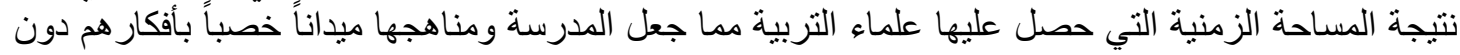

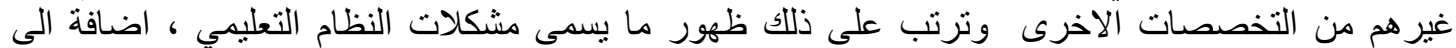

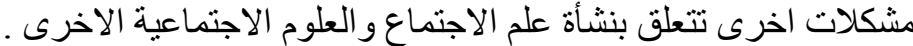
وباختصار نركز تحليلاتنا في تسأل واحد ، نستطيع من خلاعله التعرف على الألى مشكلة البحث الحالي و الذي يكون

$$
\text { على النحف نظر الاتي : }
$$

ثَالثاً : الهمية البحث البحاه

نتيجة لطغيان المشكلات التي تظهر على الو اقع الاجتماعي في المدارس من جر اء المئ المناهج ووسائل ايضاحها ،

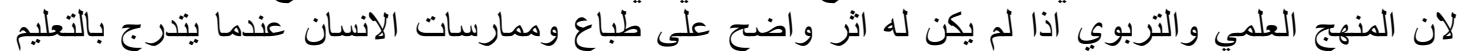

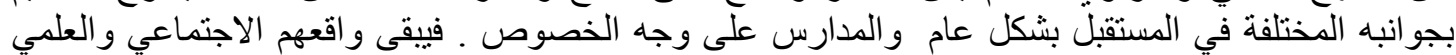

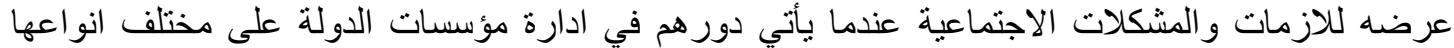

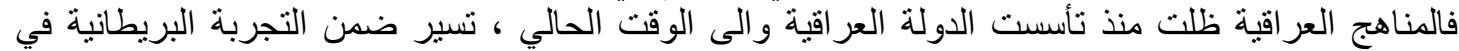

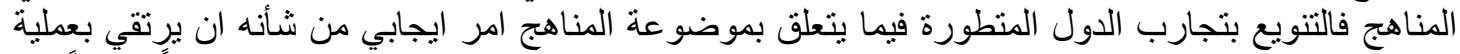

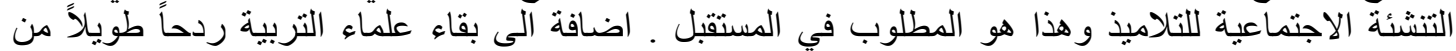

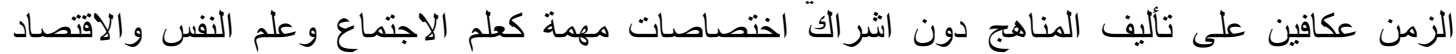

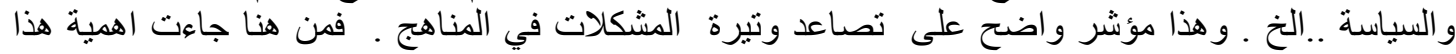

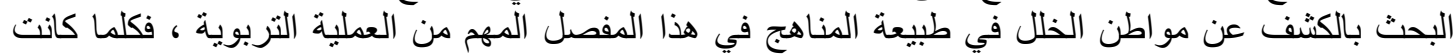

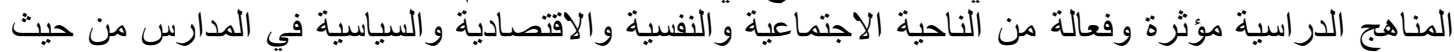

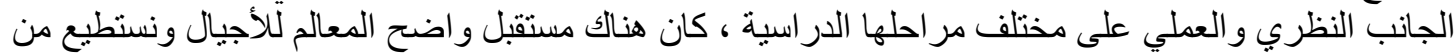

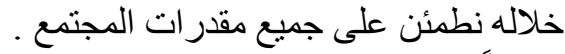
رابعاً : الهداف البحن البحث - يهدف البحث الى التعرف على التجارب والخبرات الواردة في الاتجاه النظري الاجتماعي للمنهج المدرسي . 
مبلحت (لفنون والأدب وعلوه الإنسانيات والبغتهماع Journal of Arts, Literature, Humanities and Social Sciences

ISSN online: 2414 - 3383

ISSN print: 2616 - 3810

\section{9 دِيسوبر}

Volume (47)
(47) العدد (2019)

December 2019
¿ALLHSS

WWw.jalhss.com

خامساً : تحديد المفاهيم والمصطلحات العلمية للبحث

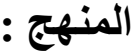

هو مقرر در اسي او تدريبي ، او على انه مواد دراسية تقرر على احدى الصفوف او المر احل الدر اسية(1).

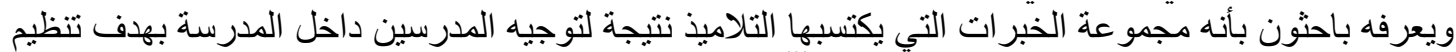

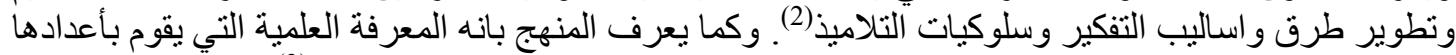

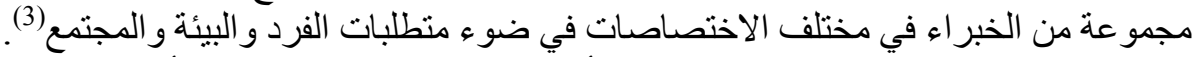

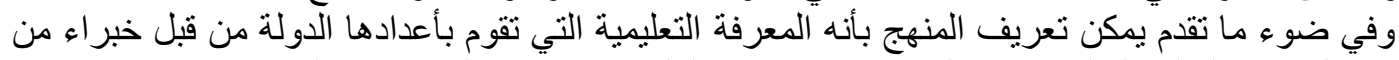

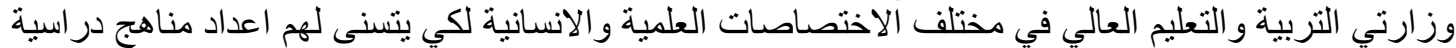

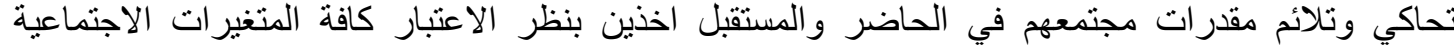

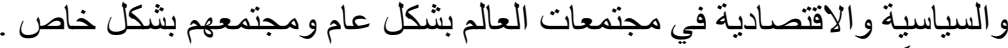

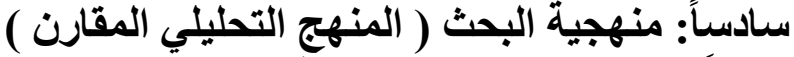
سابعاً : بعض الاتجاهات النظرية النظية في المنهج :

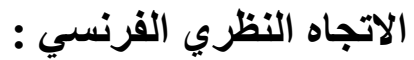

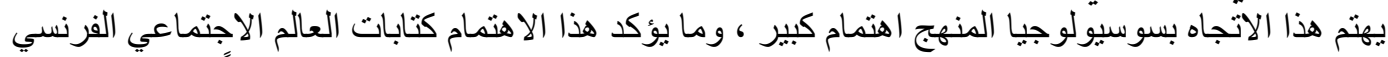

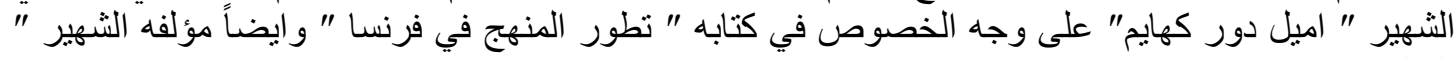

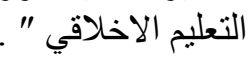
حيث حرص هذا العالم ان ييرز نظريته عن التضامن الاجتماعي عن طريق اهمية التركيز على النظام

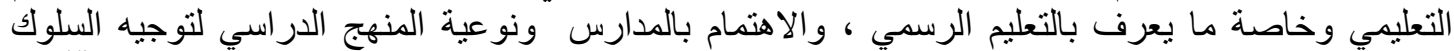

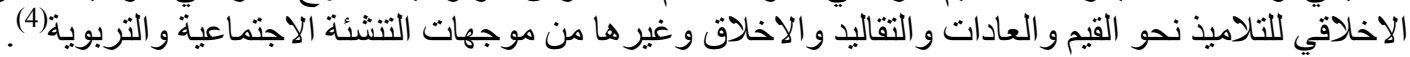

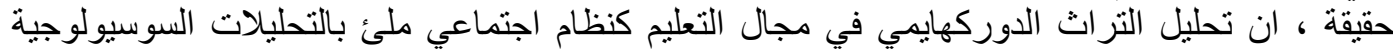

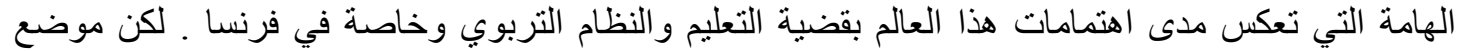

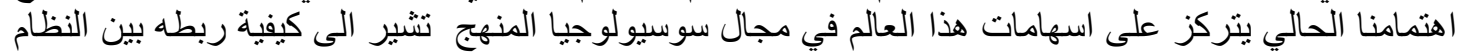

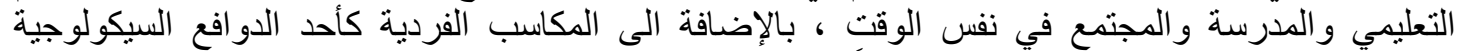

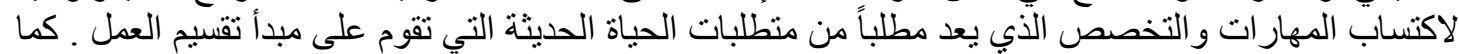

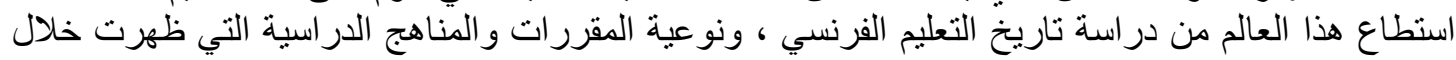

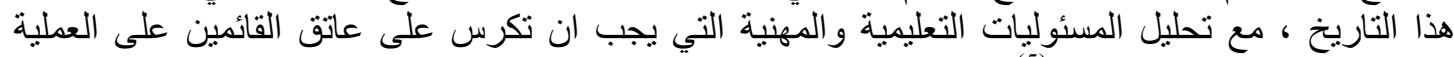

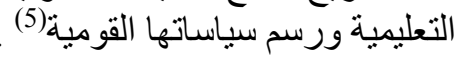
و وفي نفس الوقت استطاع هذا العالم ، ان بؤكد على اهية دولية دور الاسرة ، و واماكن العبادة في العملية التعليمية

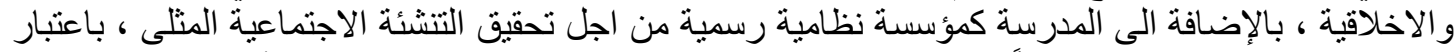

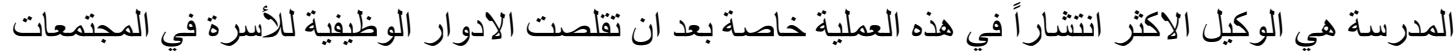

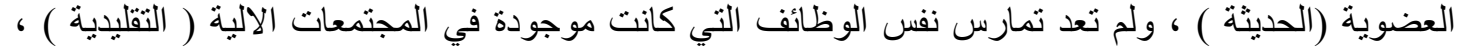

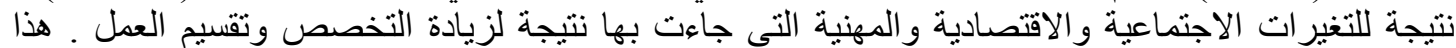

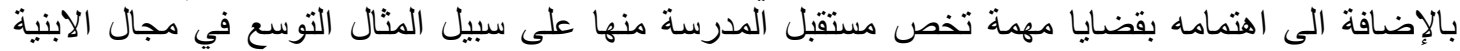

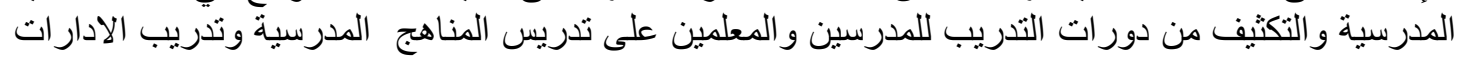

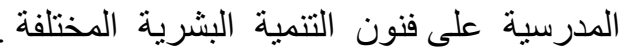

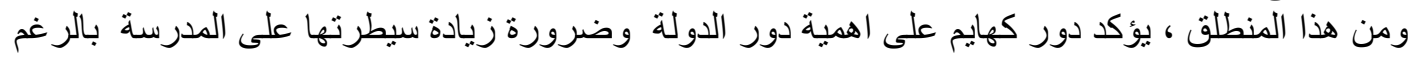

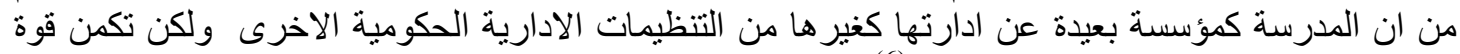

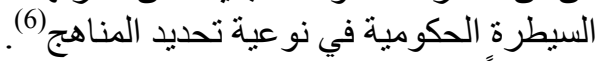

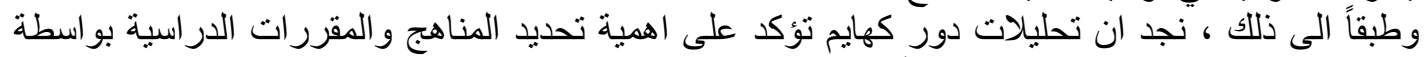

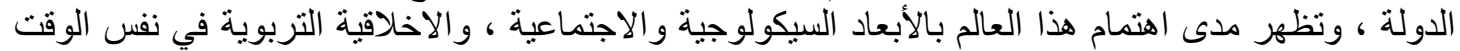

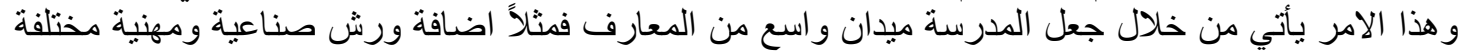
الاختصاصات في المدارس لكي ينذمج الجانب النظري مع الجانب العملي لدى التناميذ وبالتالي تصني التيح المدرسة

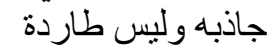


مبلحت (لفنون والأدب وعلوه الإنسانيات والبانتهاع Journal of Arts, Literature, Humanities and Social Sciences

ISSN online: 2414 - 3383

ISSN print: 2616 - 3810

\section{9 دِيسوبر} Volume (47)
العدد (47)

December 2019

\section{¿ALHSS} www.jalhss.com

حيث يظهر ان للتعليم جوانب مختلفة ومتعددة الاوجه على الثخصية الفردية للتلاميذ او النشئ في الوقت الته

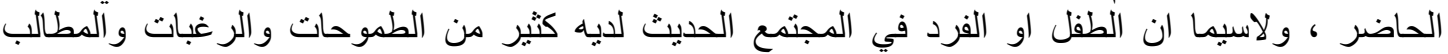

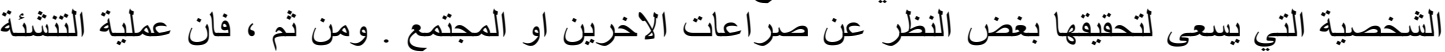

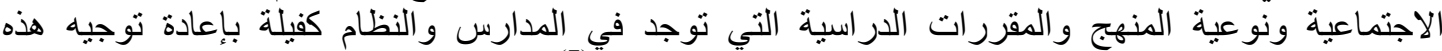

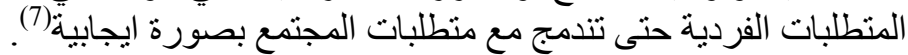

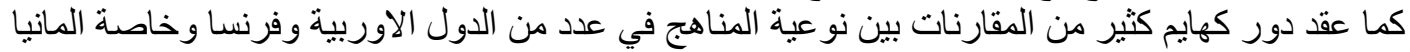

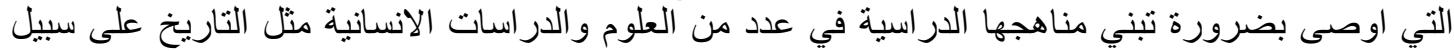

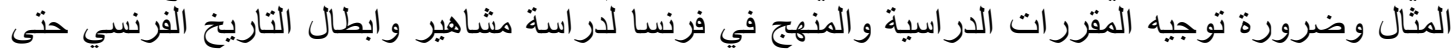
تخلق نوع من الولاء و الانتماء و التضحية عند التناميذ في المدارس وذللك عن طريق التخطيط العلمي للمنهج

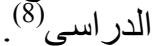

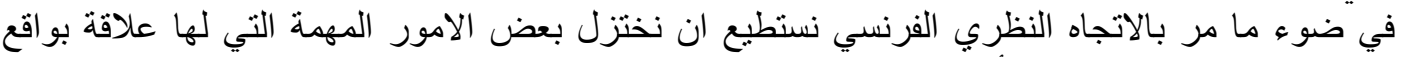

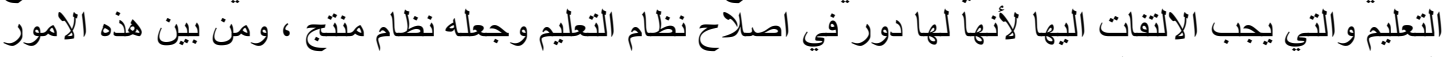

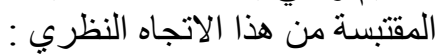

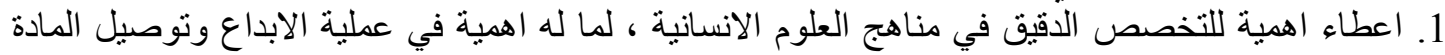

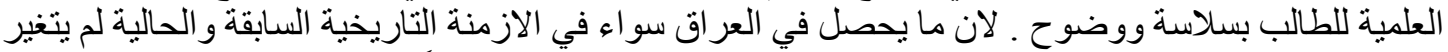

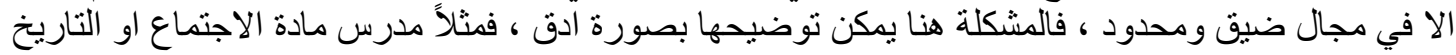

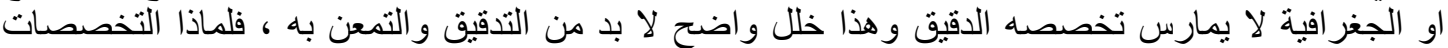

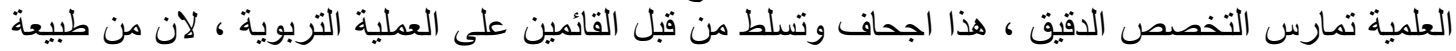

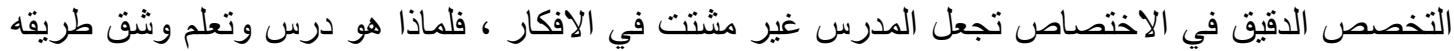

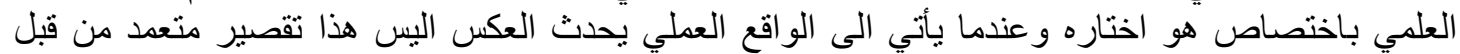

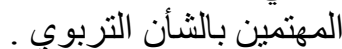

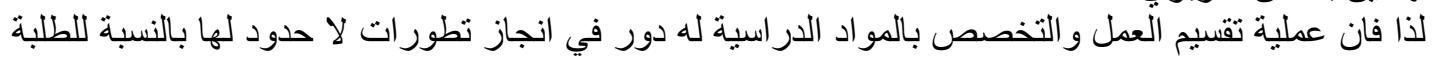

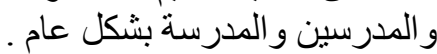

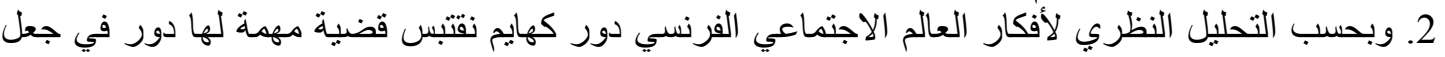

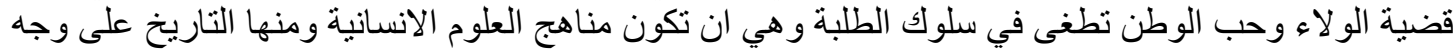

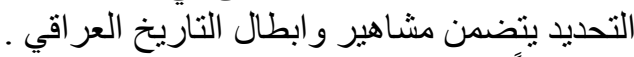

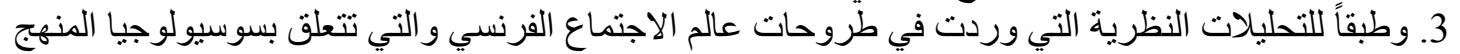

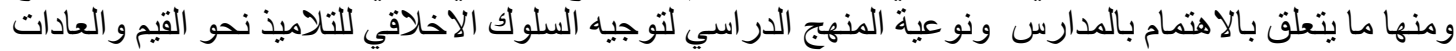

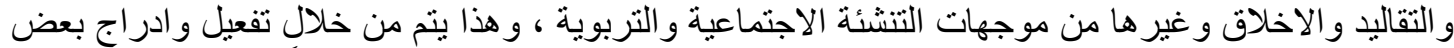

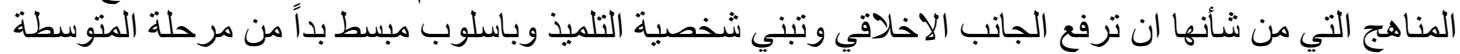

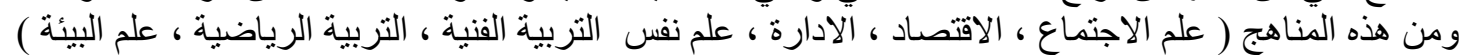

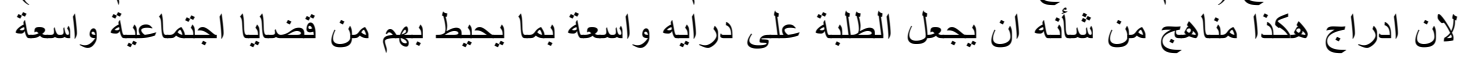

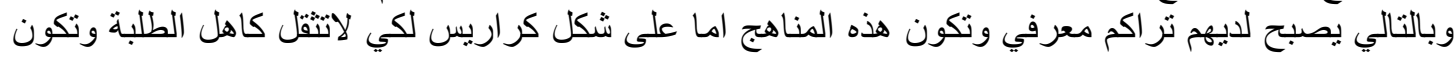

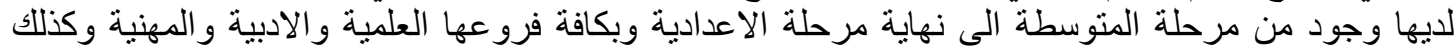

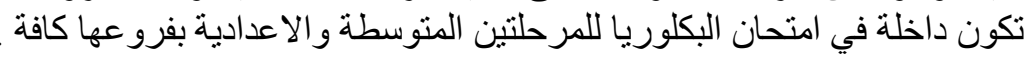

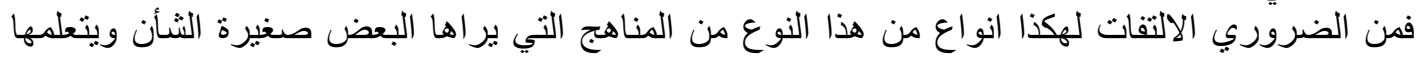

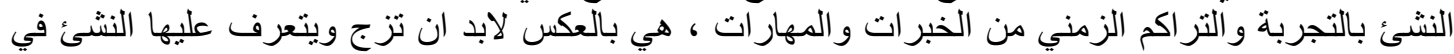

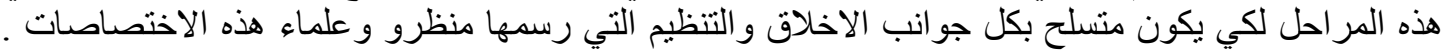

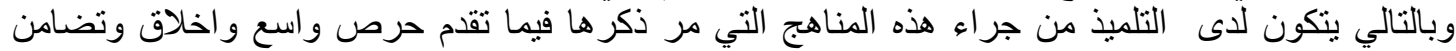

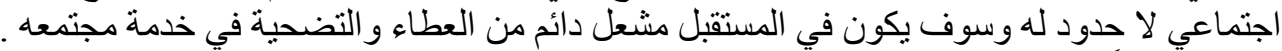

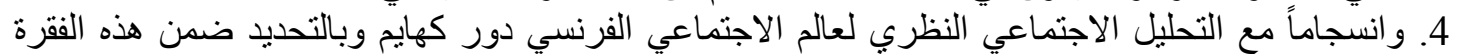

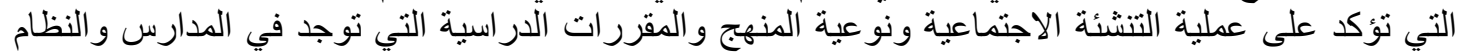
هي كفيلة بإعادة نوجيه هذه المنطلبات الفردية حتى تندمج مع منطلبات المجتمع بصورة اليجابية ـ فالتنشئة 


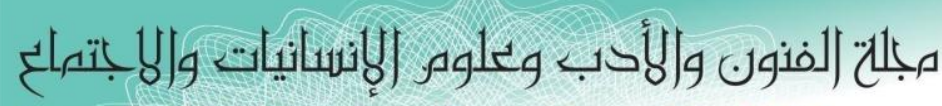
Journal of Arts, Literature, Humanities and Social Sciences

ISSN online: 2414 - 3383

ISSN print: 2616 - 3810

\section{9 ديسمبر}

Volume (47)
العدد (47)

December 2019

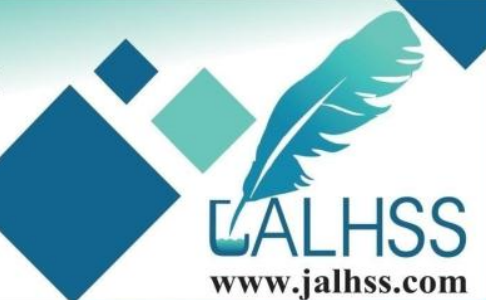

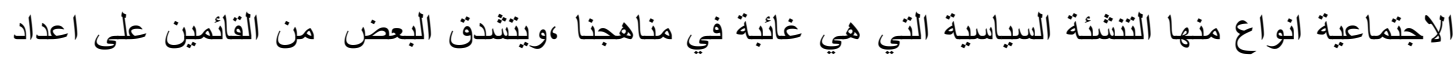

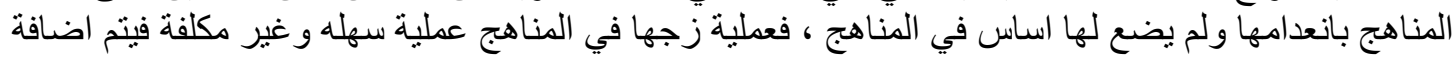

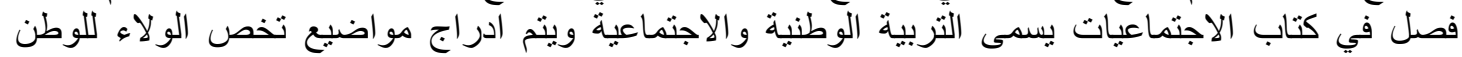

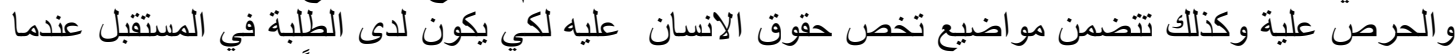

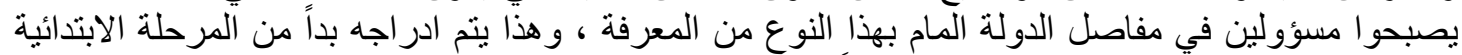

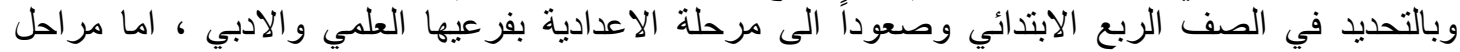

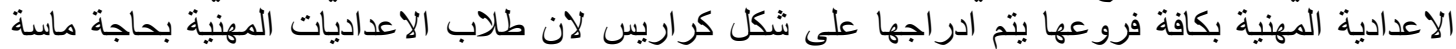

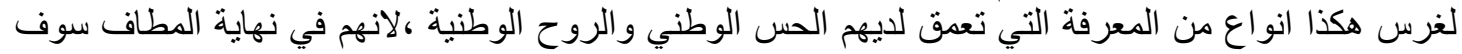

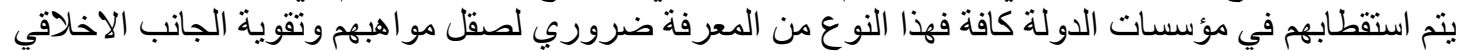

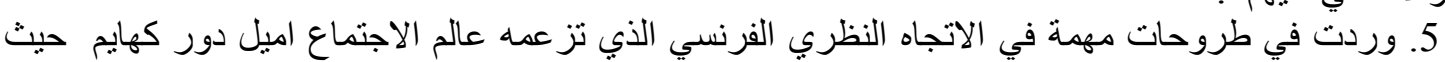

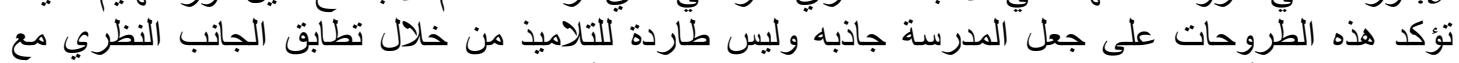

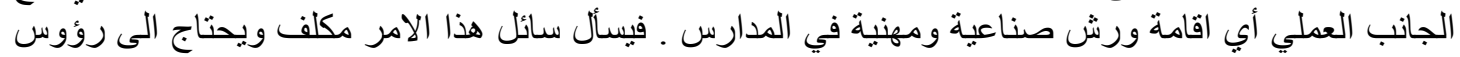

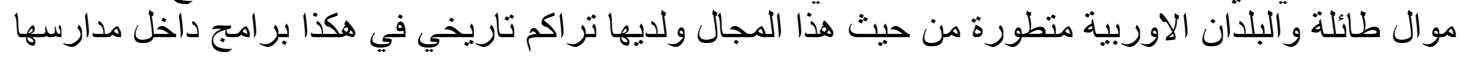

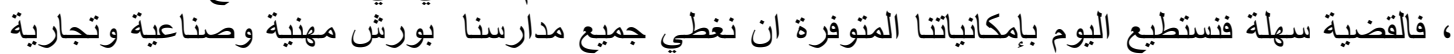

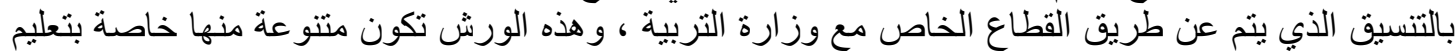

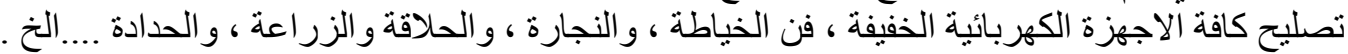

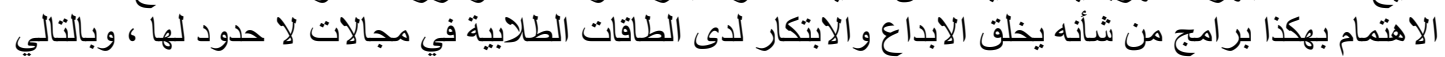

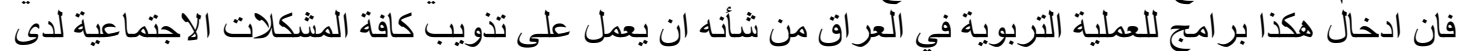

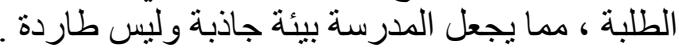

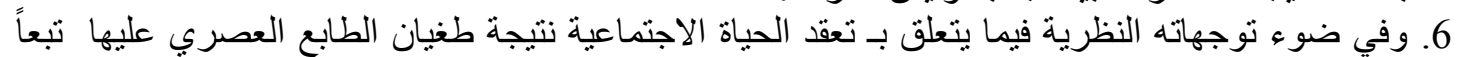

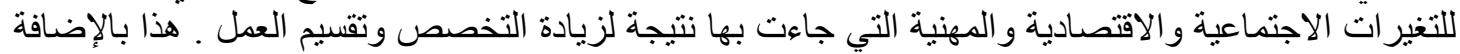

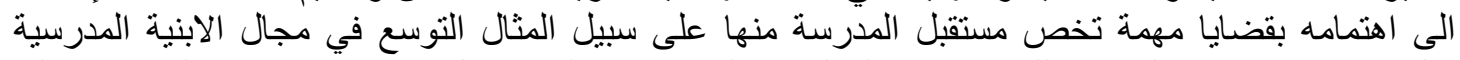

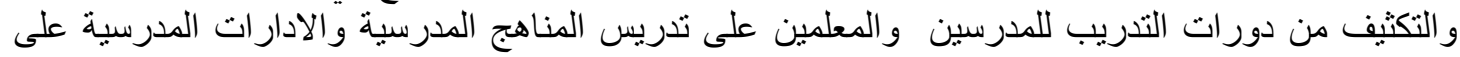

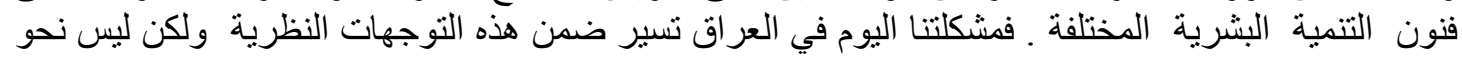

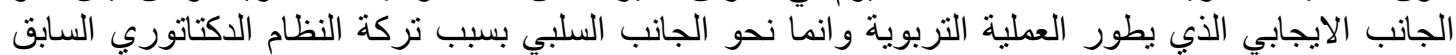

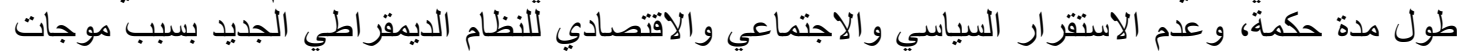

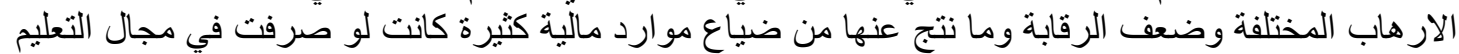

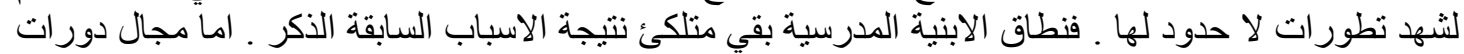

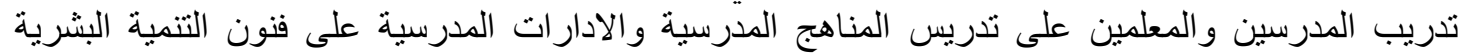

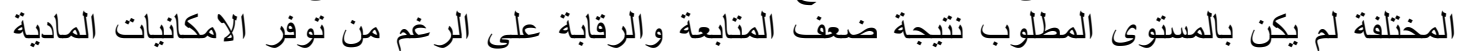

و والعلمية.

7. وتلازماً مع التوجهات النظرية للعالم الاجتماعي اميل دوركهايم ، نجد ان تحليلاته تؤكد على اهمية تحديد

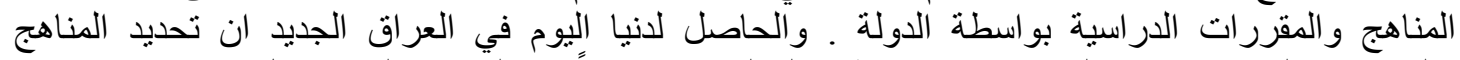

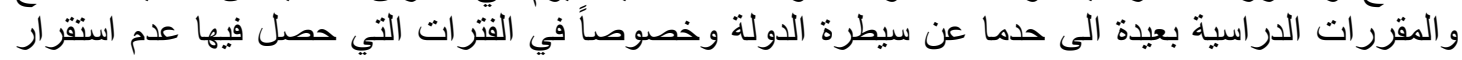

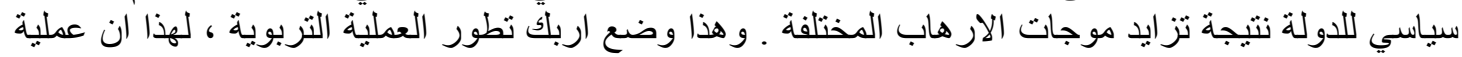

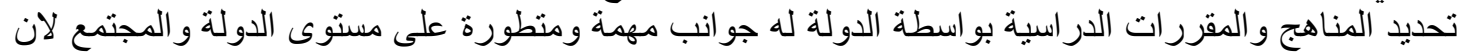

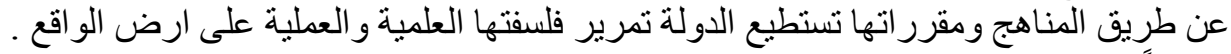

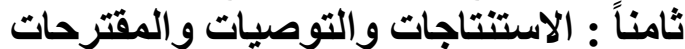

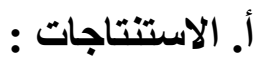

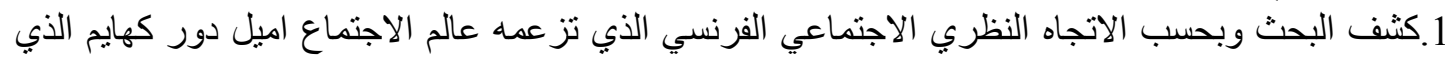

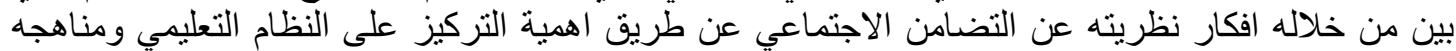
وخاصة ما يعرف بالتعليم الرسمي . 


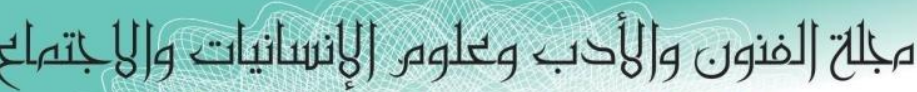
Journal of Arts, Literature, Humanities and Social Sciences

ISSN online: 2414 - 3383

ISSN print: 2616 - 3810

\section{9 دِيسوبر}

Volume (47)
العدد (47)

December 2019

\section{¿ALHSS}

www.jalhss.com

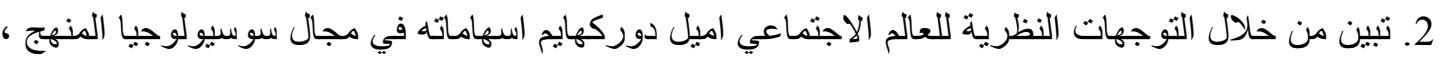

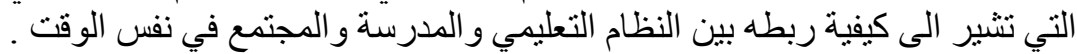

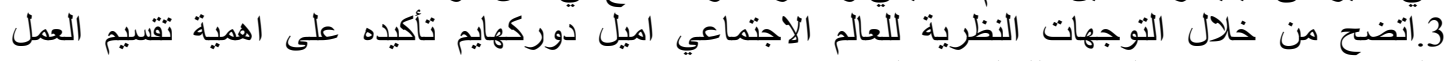

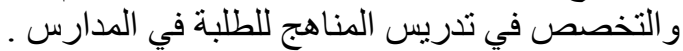

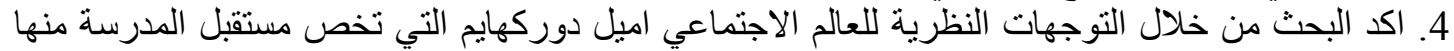

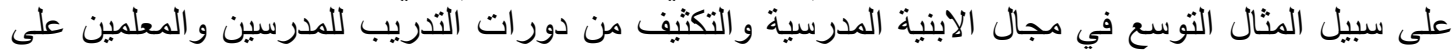

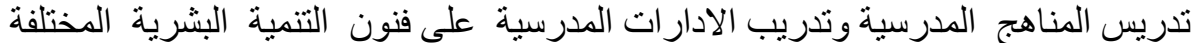

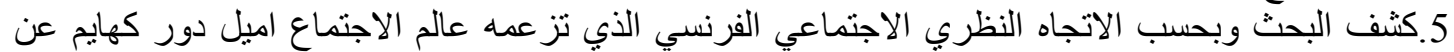

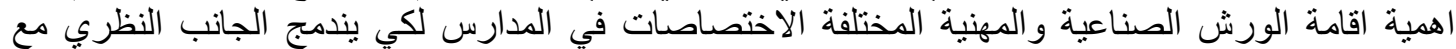

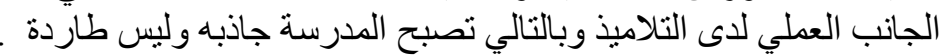

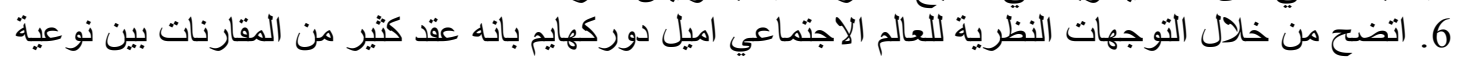

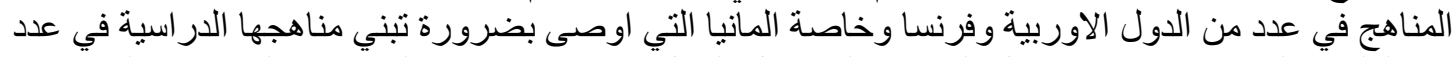

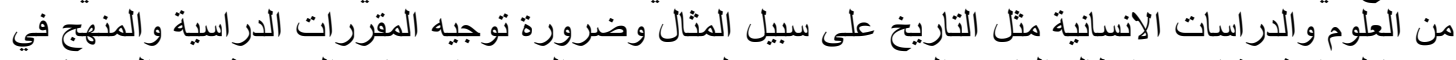

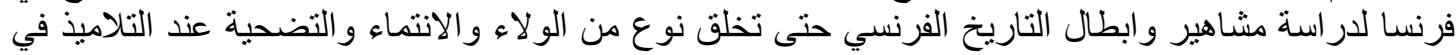

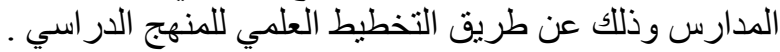

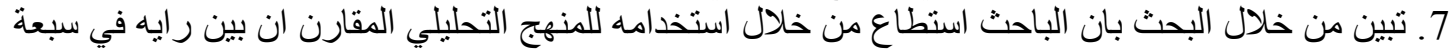

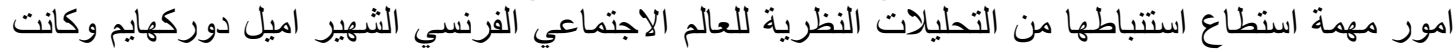

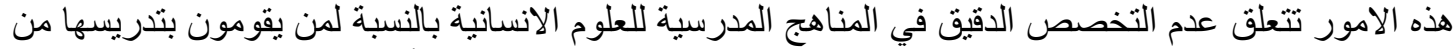

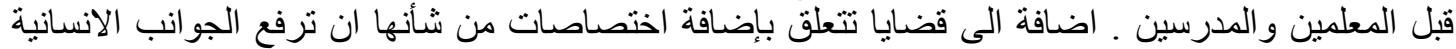

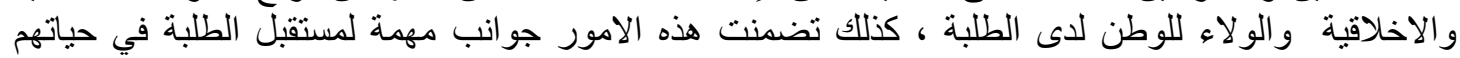

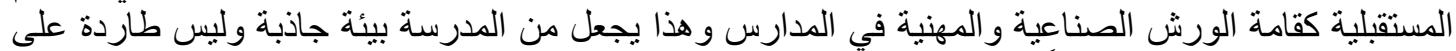

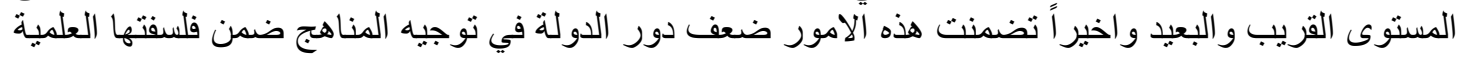

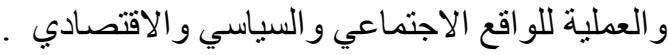
1. يوصي البحث الجهات المسؤولة بتفعيل ومتابعة قضية التخصص الدقيق في مناهج العلوم الانسانية ، لما له له

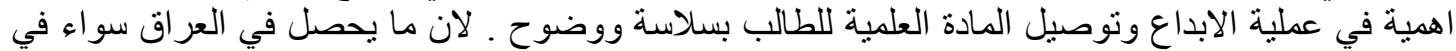

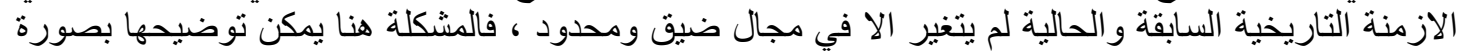

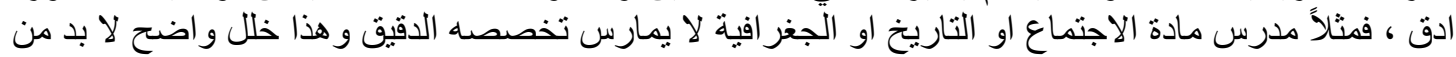

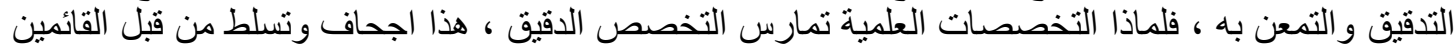

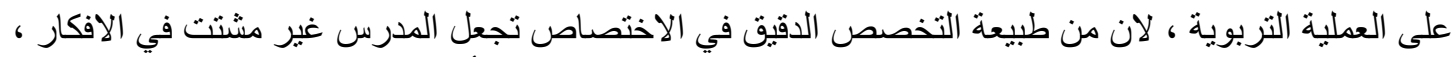

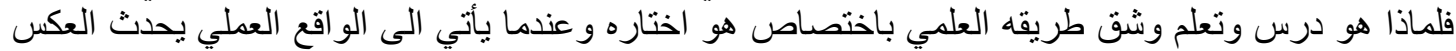

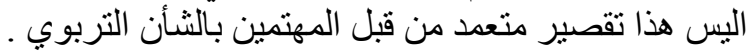

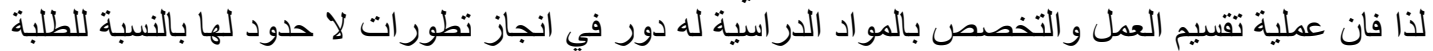

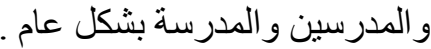
2. يوصي البحث الجهات المسؤولة عن العملية التربوية وبحسب التحليل النظري لأفكار العالم الاجنماعي

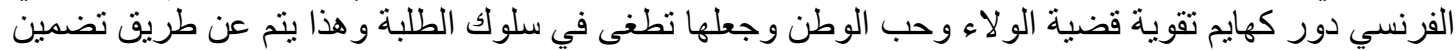

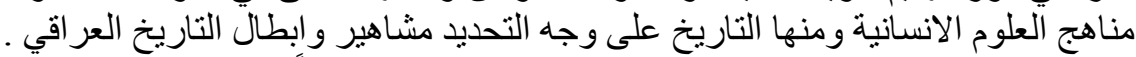

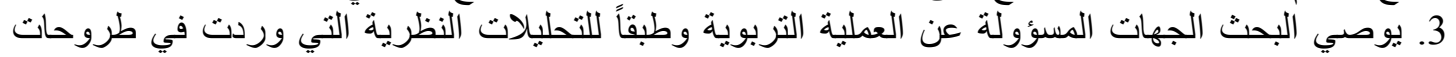

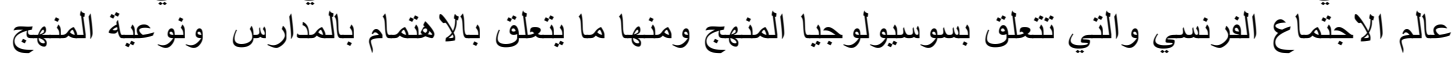

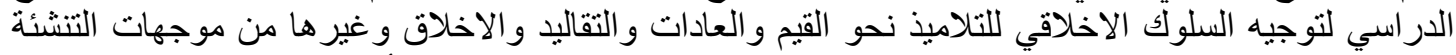

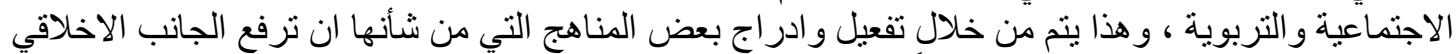

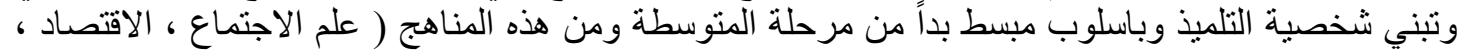


مبلحت (لفنون والأدب وعلوه الإنسانيات والبانتهاع Journal of Arts, Literature, Humanities and Social Sciences

ISSN online: 2414 - 3383

ISSN print: 2616 - 3810

\section{ديسمبر 2019 \\ Volume (47)}

العدد (47)

December 2019

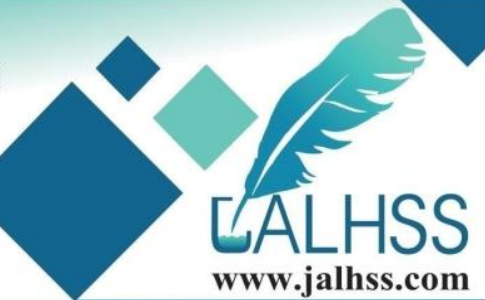

الادارة ، علم نفس التربية الفنية ، التربية الرياضية ، علم البيئة ) لان ادراج هكذا مناهج من شأنه ان يجعل

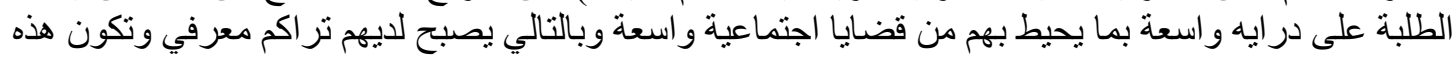

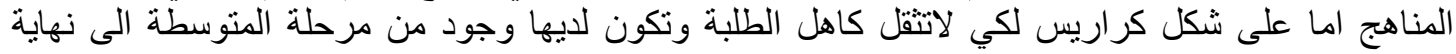
مرحلة الاعدادية وبكافة فرو عها العلمية والادبية والاية والمهنية وكذللك تكون داخلة في امتحان البكلوريا للمرحلتين

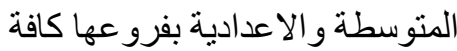

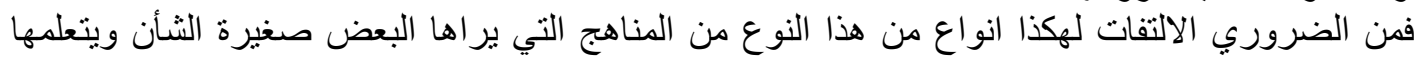

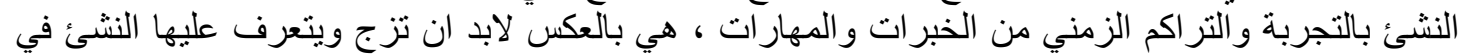

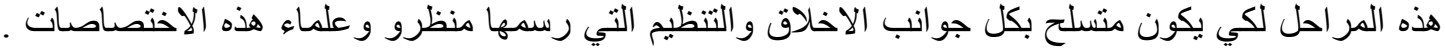

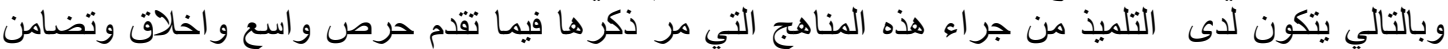
اجتماعي لا حدود لله وسوف يكون في المستقبل مشعل دائُ من العطاء و التضحية في في خدمة مجنمعه .

4. يوصي البحث الجهات المسؤولة عن العملية التربوية وبحسب التحليل النظري لأفكار العالم الاجتماعي

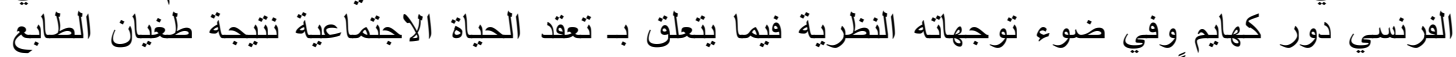

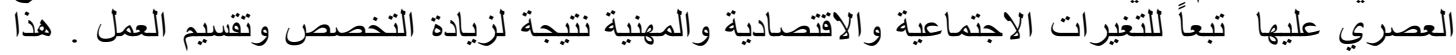

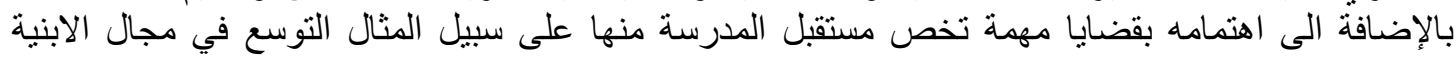

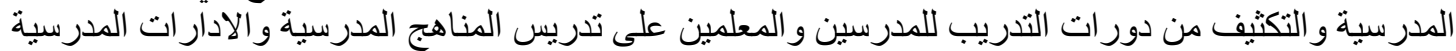

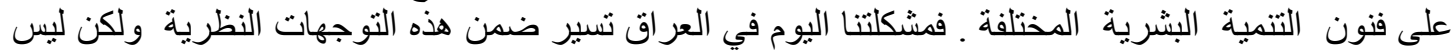

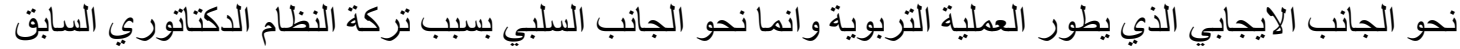

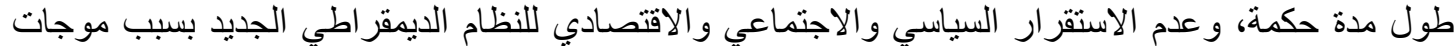

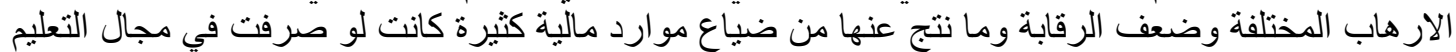

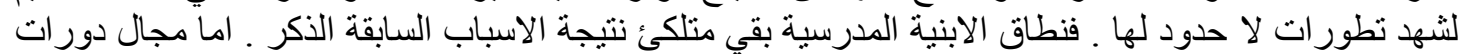

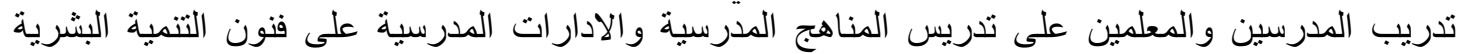

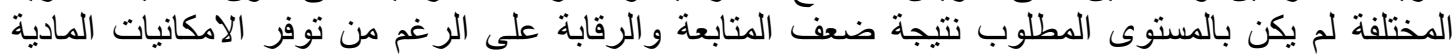

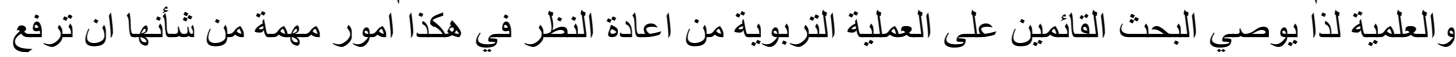
من تقدم العملية التربوية وتذوب مشكلاتها. 1. يقترح البحثث الحالي بالانسجام مع التحليل الاجتماعي النظري لعالم الاجتماعي الفرنسي دور كهايم

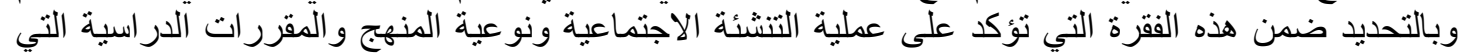

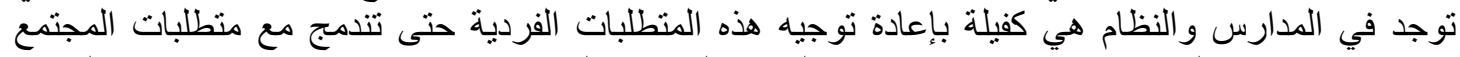

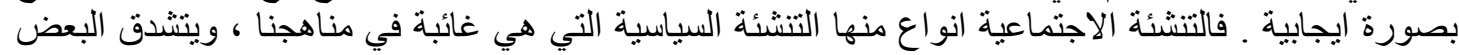

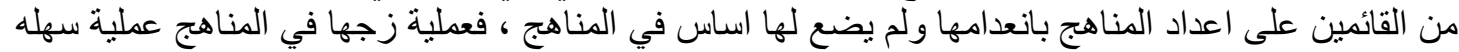

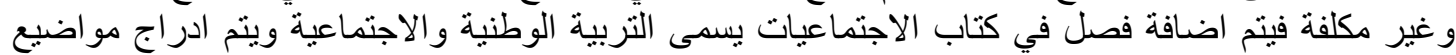

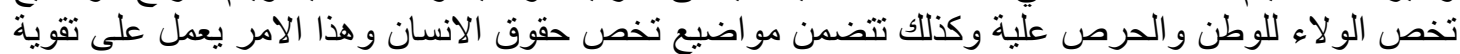

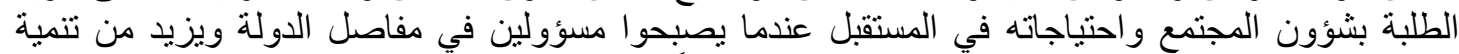

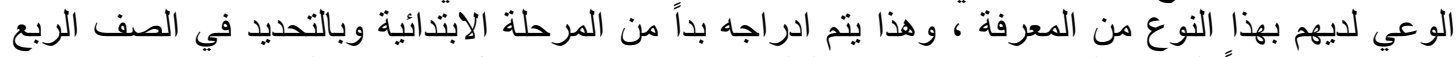

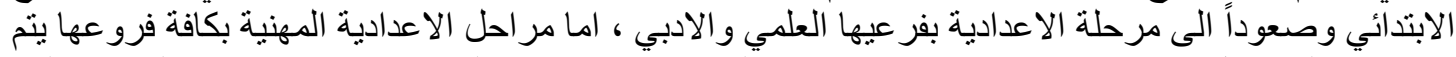

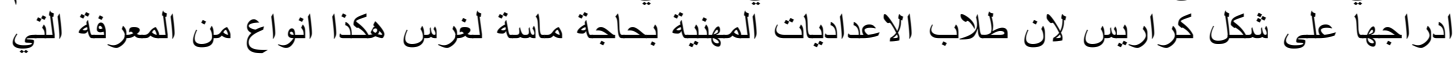

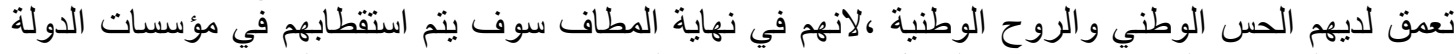

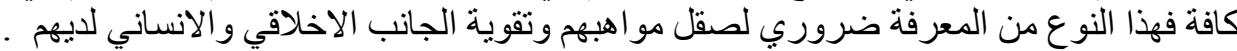

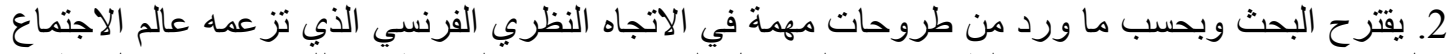

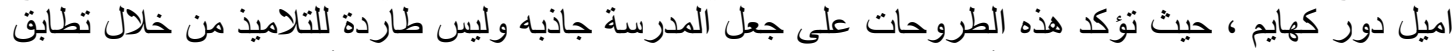

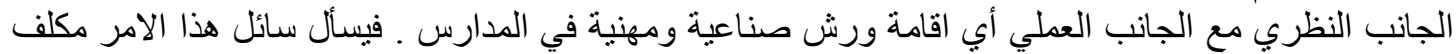




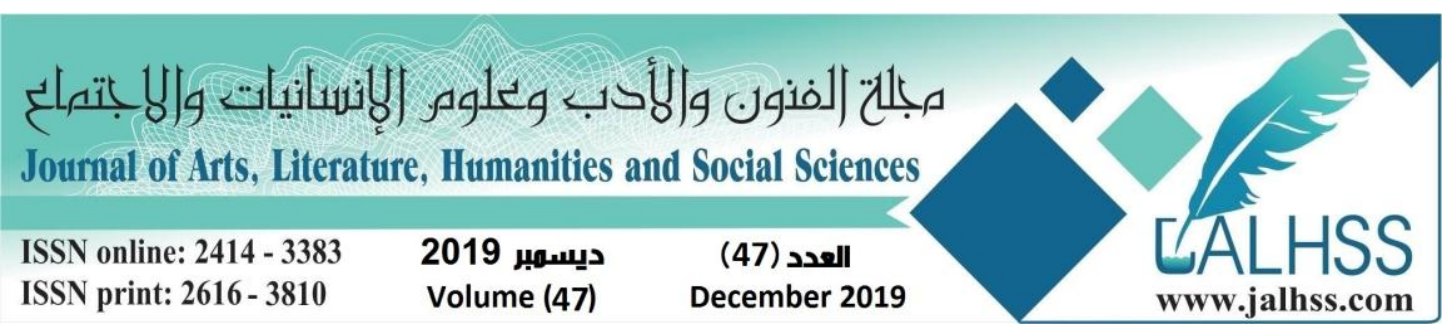

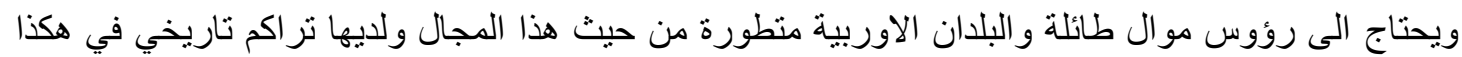

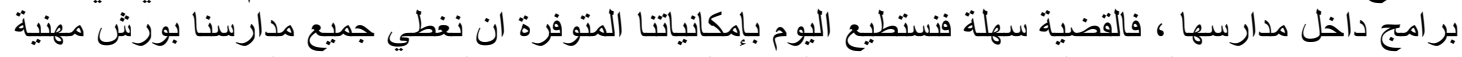

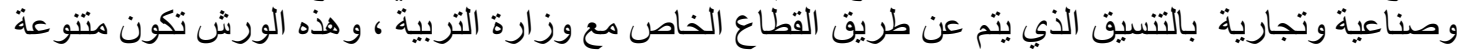

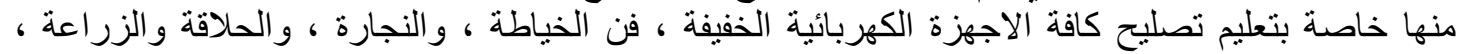

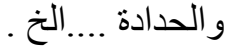

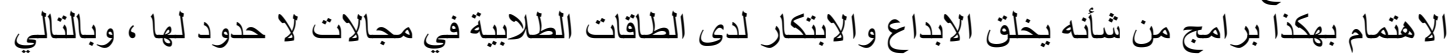

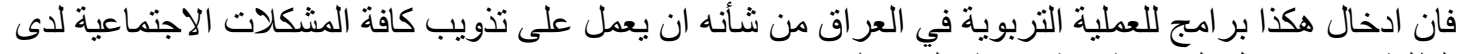

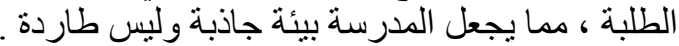

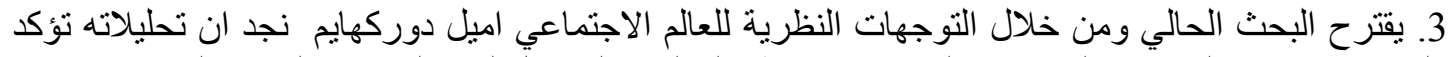

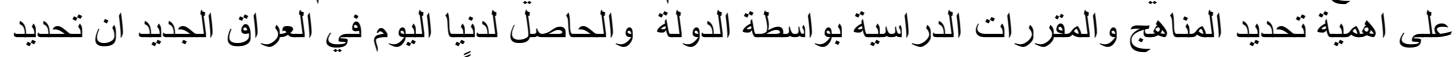

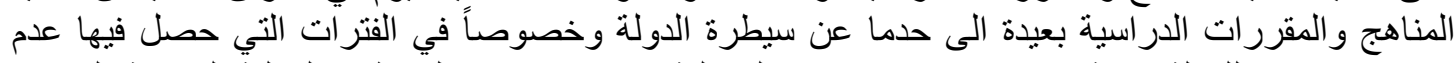

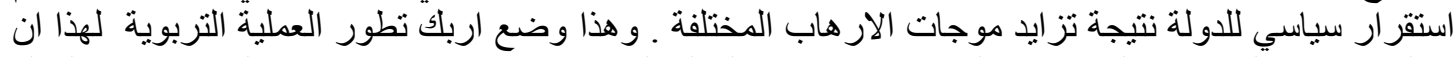

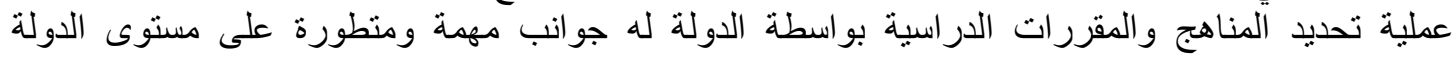

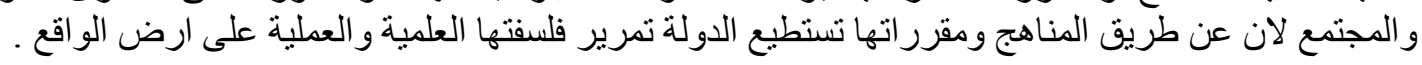

1.Durkheim,E,Moral Education : London ,p33,1961.

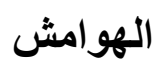

2. Durkheim, E, Evolution Pedagogique en France ,Paris ,p45,1969.

3. Durkheim ,E, Education and Sociology, N.Y. Free Press,p25,1956.

4.Giddens, A, Durkheim, London : Fontana/Collins ,pp63-79, 1981.

5.الكلزة،رجب احمد واخرون ، المنهج المدرسي : نظرياته وتنظيماته ( مصر: القاهرة ،دار الثقافة للنشر والتوزيع ،

7.Rural History Centre.2005

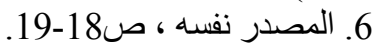

www.rdg.ac.uk/Insists/im/rural/hist .html.

8. سعادة ، جودت احمد واخرون ، تنظيمات المناهج وتخطيطها وتطوير ها (مصر: القاهرة ،دار الثقافة للنشر والتوزيع ،

2003) 2003

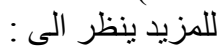

ـ كريم ، احمد عبد الكاظم ، الجودة التربوية في المنظور الاجتماعي التفاعلي ( العراق : تربية القادسية ، المؤتمر الثالث

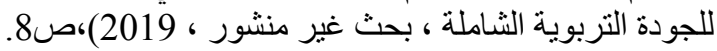

1. المصلزةر،رجب احمد واخرون ، المنهج المدرسي : نظرياته وتنظيماته ( مصر : القاهرة ،دار الثقافة للنشر

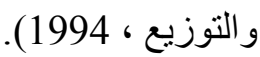

2. سعادة ، جودت احمد و واخرون ، تنظيمات المناهج وتخطيطها وتطويرها (مصر : القاهرة ،دار الثقافة للنشر

والتوزيع ، 2003)

3.Durkheim,E,Moral Education : London ,p33,1961.

4. Durkheim, E, Evolution Pedagogique en France ,Paris ,p45,1969.

5. Durkheim ,E, Education and Sociology, N.Y. Free Press,p25,1956.

6.Giddens, A, Durkheim, London : Fontana/Collins ,pp63-79,1981.

7.Rural History Centre 2005.

www.rdg.ac.uk/Insists/im/rural/hist .html.

8. كريم ، احمد عبد الكاظم ، الجودة التربوية في المنظور الاجتماعي التفاعلي ( العراق : نربية القادية ،

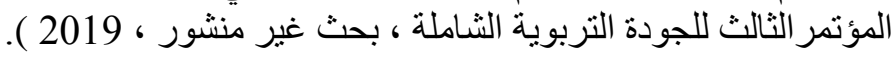




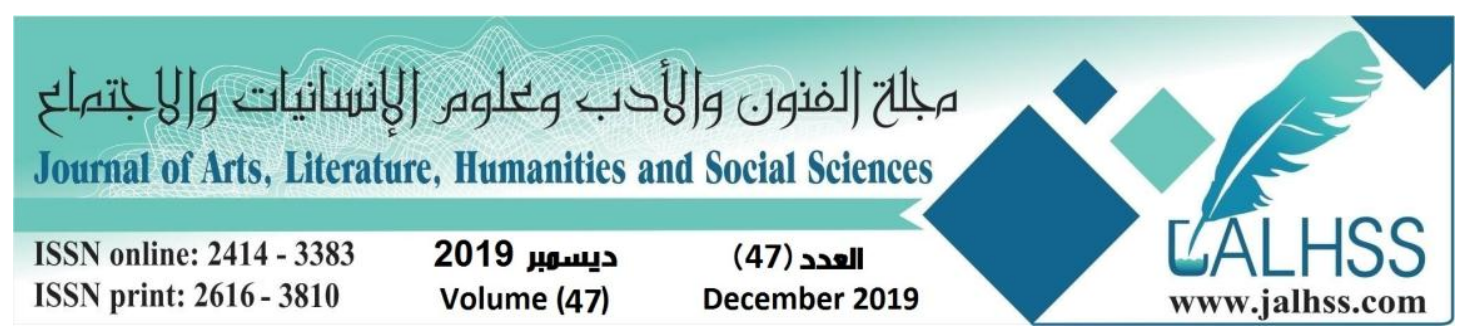

\section{References}

1.El-Kalza, Ragab Ahmed and Others, School Curriculum: Theories and Organization (Egypt: Cairo, Dar Al-Thaqafa for Publishing and Distribution, 1994).

2. HE, Jawdat Ahmed et al., Curriculum Organization, Planning and Development (Egypt: Cairo, Dar Al Thaqafa for Publishing and Distribution, 2003).

3.Durkheim, E, Moral Education: London, p33,1961.

4. Durkheim, E, Evolution Pedagogique en France, Paris, p45,1969.

5. Durkheim, E, Education and Sociology, N.Y. Free Press, p25,1956.

6.Giddens, A, Durkheim, London: Fontana/Collins, pp63-79, 1981.

7.Rural History Center 2005. www.rdg.ac.uk/Insists/im/rural/ hist .html.

8. Kareem, Ahmad Abdul Kadhim, Educational Quality in an Interactive Social Perspective (Iraq: Qadisiyah Education, Third Conference on Total Educational Quality, unpublished research, 2019). 